\title{
Assessing the impact of climate change on water resources in Iran
}

\author{
Karim C. Abbaspour, ${ }^{1}$ Monireh Faramarzi, ${ }^{1}$ Samaneh Seyed Ghasemi, ${ }^{1}$ and Hong Yang ${ }^{1}$ \\ Received 27 November 2008; revised 16 July 2009; accepted 27 July 2009; published 28 October 2009. \\ [1] As water resources become further stressed due to increasing levels of societal \\ demand, understanding the effect of climate change on various components of the water \\ cycle is of strategic importance in management of this essential resource. In this study, we \\ used a hydrologic model of Iran to study the impact of future climate on the country's \\ water resources. The hydrologic model was created using the Soil and Water Assessment \\ Tool (SWAT) model and calibrated for the period from 1980 to 2002 using daily river \\ discharges and annual wheat yield data at a subbasin level. Future climate scenarios for \\ periods of 2010-2040 and 2070-2100 were generated from the Canadian Global Coupled \\ Model (CGCM 3.1) for scenarios A1B, B1, and A2, which were downscaled for 37 \\ climate stations across the country. The hydrologic model was then applied to these \\ periods to analyze the effect of future climate on precipitation, blue water, green water, and \\ yield of wheat across the country. For future scenarios we found that in general, wet \\ regions of the country will receive more rainfall while dry regions will receive less. \\ Analysis of daily rainfall intensities indicated more frequent and larger-intensity floods in \\ the wet regions and more prolonged droughts in the dry regions. When aggregated to \\ provincial levels, the differences in the predictions due to the three future scenarios were \\ smaller than the uncertainty in the hydrologic model. However, at the subbasin level \\ the three climate scenarios produced quite different results in the dry regions of the \\ country, although the results in the wet regions were more or less similar.
}

Citation: Abbaspour, K. C., M. Faramarzi, S. S. Ghasemi, and H. Yang (2009), Assessing the impact of climate change on water resources in Iran, Water Resour. Res., 45, W10434, doi:10.1029/2008WR007615.

\section{Introduction}

[2] Nearly all regions of the world are expected to experience a net negative impact of climate change on water resources and freshwater ecosystems [Intergovernmental Panel on Climate Change (IPCC), 2007]. The intensity and characteristics of the impact, however, can vary significantly from region to region. Some regions are likely to experience water shortages. Coupled with increasing demand, this is likely to result in large increases in the number of people at risk of water scarcity. Rising sea levels in heavily populated coastal regions, on the other hand, may threaten the lives and livelihood of millions of people. The frequency of floods and droughts are certain to increase in much of the world. The economic cost is likely to be high and the overall crop yield may decline, increasing the risk of poverty and hunger. For a long-term strategic planning of a country's water resources in the face of the evolving climate change impacts, it is important that these effects be quantified with a high spatial and temporal resolution.

[3] A large number of publications in the literature deal with a particular component of water balance, e.g., streamflow [Fu et al., 2007; Caballero et al., 2007], groundwater recharge [Scibek and Allen, 2006; Jyrkama and Sykes, 2007], runoff [Nunes et al., 2009], evapotranspiration [Calanca et

\footnotetext{
${ }^{1}$ Eawag: Swiss Federal Institute of Aquatic Science and Technology, Duebendorf, Switzerland.
}

Copyright 2009 by the American Geophysical Union. 0043-1397/09/2008WR007615 al., 2006], or a particular event throughout a year, e.g., low flows, peak flows [Cuo et al., 2009], extreme events [Xiong et al., 2009], and changes or shifts in seasonal processes [Thomas et al., 2007]. However, fewer publications have focused on the long-term evaluation of a basin's water balance due to climate change impacts on regional hydrologic processes. Yet this may be the most beneficial application of hydroclimatology to support long-term water resources management and planning [Serrat-Capdevila et al., 2007]. An integrated hydrological simulation model could help to study the net effect of climate change in a given region.

[4] In this paper, we report on the results of investigating the impact of climate change on water resources in Iran for the near (2010-2040) and far (2070-2100) future. Iran is a country of large climatic variability from north to south. The northern part of the country is quite wet with frequent costly floods, while the southern part is dry with large water scarcity, frequent droughts, and a large reliance on dwindling groundwater resources. To get an overall picture, we used the integrated hydrological Soil and Water Assessment Tool (SWAT) model [Arnold et al., 1998] to study the effect of climate change at a subbasin level at a monthly time step for the whole country. We specifically looked at the changes in various components of the water balance including precipitation and evapotranspiration distribution, river discharge, soil moisture, and aquifer recharge. These variables were then used to quantify the changes in water resources with respect to blue water (river discharge plus aquifer recharge) and green water (soil moisture and evapotranspiration). The 


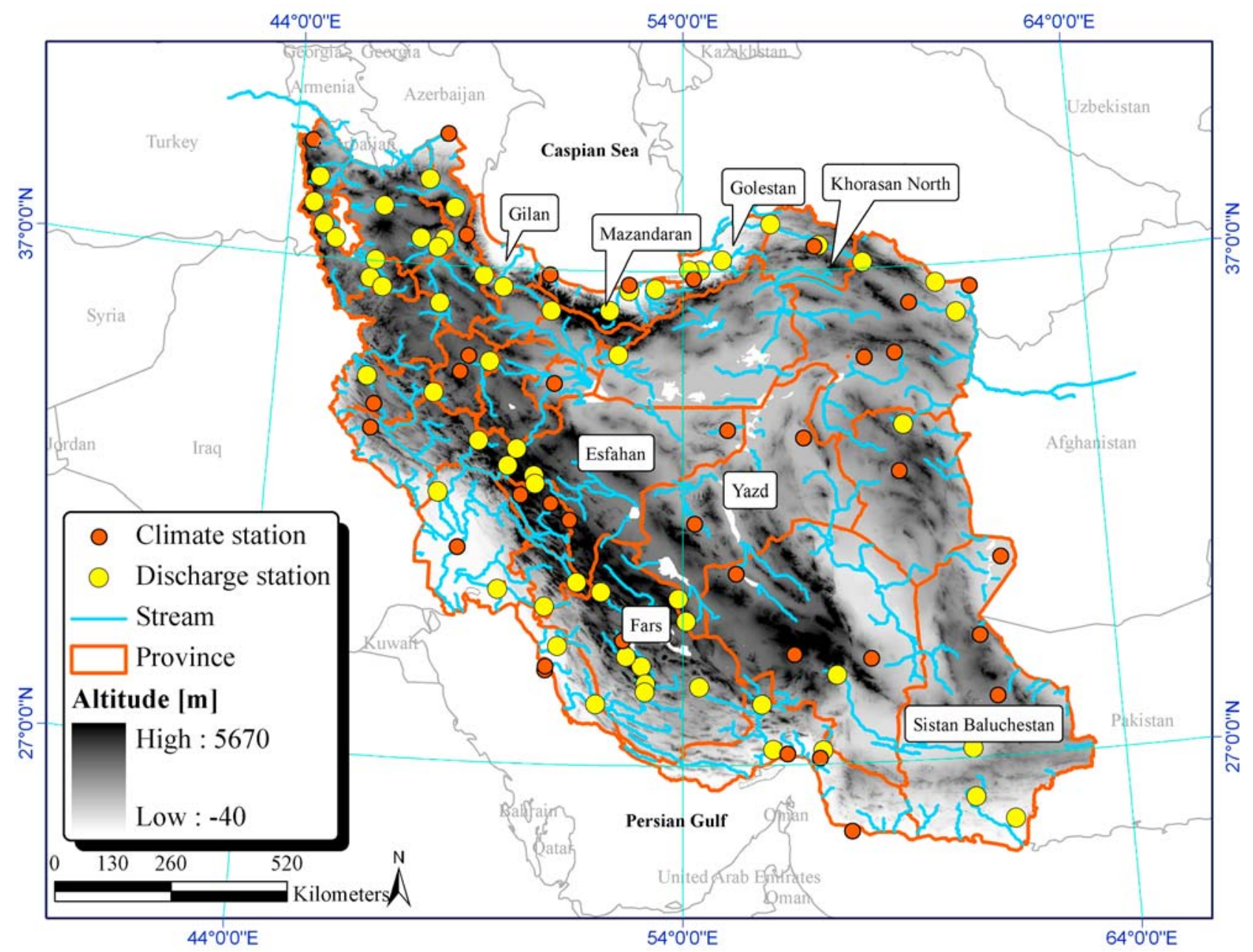

Figure 1. An overview of Iran modeling details showing the elevation, streams, climate stations, and discharge stations used in the model, as well as the provincial boundaries.

results will contribute to the scientific community's understanding of climate change impacts on water resources and provide information to support future water resources planning and management in Iran and other countries with the same climatic conditions.

[5] We used a calibrated SWAT model of Iran in this study based on modifications of the model developed originally by Faramarzi et al. [2009]. This model consisted of parameters that were expressed probabilistically, reflecting the combined uncertainties of input, model structure, and parameters. The impact on various components of the water resources of the country were quantified at the subbasin scale using a series of anomaly maps (\% deviations from historic data). In addition, the impact of climate change on flooding and droughts as well as wheat yield were also investigated. The implications of these impacts for the water and food security of the country are addressed in section 4 .

\section{Materials and Methods}

\subsection{Description of the Study Area}

[6] Iran is located between $25^{\circ}$ and $40^{\circ}$ north latitude and $44^{\circ}-63^{\circ}$ east longitude and has a total area of $1,648,000 \mathrm{~km}^{2}$ (Figure 1). The altitude varies from $-40 \mathrm{~m}$ to $5670 \mathrm{~m}$, which has a pronounced influence on the diversity of the climate.
Iran as a whole is a semiarid country. The per capita freshwater availability for the country was estimated to be around $2000 \mathrm{~m}^{3}$ per capita $\mathrm{yr}^{-1}$ in the year 2000 by Yang et al. [2003], who also predicted that it may go below $1500 \mathrm{~m}^{3}$ per capita $\mathrm{yr}^{-1}$ by 2030 due to the population growth. However, Iran has a broad spectrum of climatic conditions across regions with significant rainfall variability (averages of $2000 \mathrm{~mm} \mathrm{yr}^{-1}$ in the northern and western provinces, and $120 \mathrm{~mm} \mathrm{yr}^{-1}$ in the central and eastern parts of the country) and temperature variability (extremes of $-20^{\circ} \mathrm{C}$ in the southwest to $50^{\circ} \mathrm{C}$ along the Persian Gulf). Climate change is expected to have different impacts on rainfall and temperature patterns across regions and consequently on the spatial and temporal distributions of the various components of water resources. More details of the study area are given by Faramarzi et al. [2009].

[7] Roughly $37 \times 10^{6}$ ha of Iran's total surface area is arable land. Of this, $18.5 \times 10^{6}$ ha are devoted to horticulture and field crop production [Keshavarz et al., 2005]. About $9 \times 10^{6}$ ha of this land are irrigated using traditional and modern techniques, and $10 \times 10^{6}$ ha are rain-fed. Wheat is the core commodity of the Iranian food and agriculture system and is grown on nearly $60 \%$ of the country's arable land. The average yield for irrigated wheat is approximately $3.0 \mathrm{t} \mathrm{ha}^{-1}$, compared with $0.95 \mathrm{t} \mathrm{ha}^{-1}$ for 


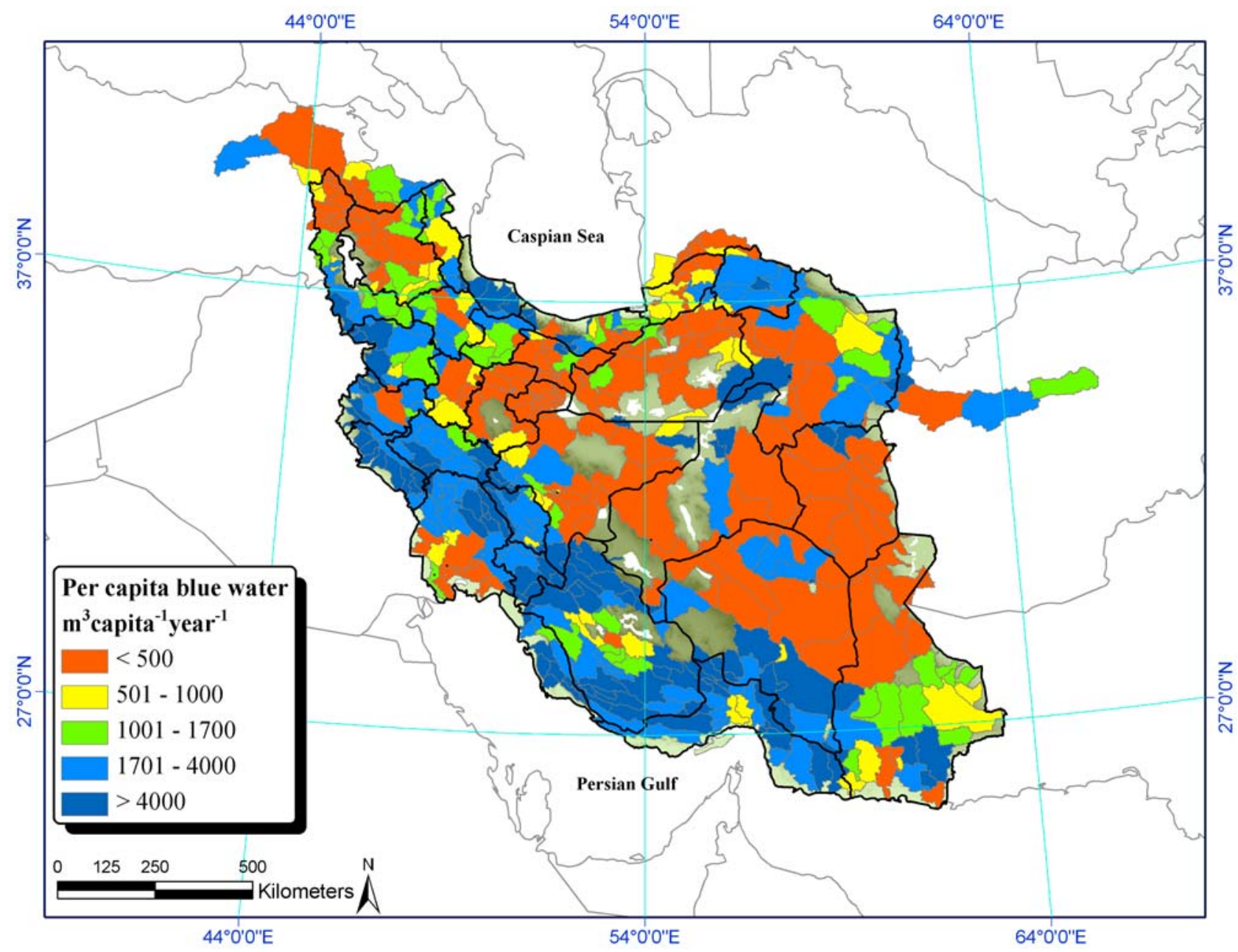

Figure 2. Distribution of per capita blue water resources for the period of 1980-2002 based on the population of 2005 .

rain-fed wheat [Food and Agricultural Organization (FAO), 2005].

[8] In Iran, more than $90 \%$ of the total water withdrawal is used in the agricultural sector, mostly for irrigation. About $50 \%$ of the irrigation water is from surface sources and the other $50 \%$ is from groundwater [Ardakanian, 2005]. Owing to the traditional method of irrigation and water conveying systems, the irrigation water use efficiency varies between $15 \%$ and $36 \%$. Therefore a large fraction of diverted water is lost to evaporation and percolation.

[9] In general, most of the country suffers from water resources scarcity. Figure 2 shows the per capita blue water resources distribution in the period of 1980-2002 based on the population of the year 2005 [see Faramarzi et al., 2009]. The spatial distribution of water resources availability shows a large variation across the country. The five water stress levels given in Figure 2 follow the widely used water stress indicators defined by Falkenmark et al. [1989] and Rijsberman [2006]. Taking $1700 \mathrm{~m}^{3}$ per capita as the water scarcity threshold, about 46 million people living on about $59 \%$ of the country's area were subject to water scarcity.

\subsection{The Hydrologic Simulator (SWAT)}

[10] SWAT is a computationally efficient simulator of hydrology and water quality at various scales. SWAT was developed to assess the impacts of land use changes on water supplies and erosion in large-scale catchments. The model includes procedures to describe how $\mathrm{CO}_{2}$ concentration, precipitation, temperature and humidity affect plant growth, evapotranspiration, snow and runoff generation, among other variables, and therefore is also used to investigate climate change impacts [Eckhardt and Ulbrich, 2003; Fontaine et al., 2001; Stonefelt et al., 2000].

[11] The program has been used in many large-scale international applications [e.g., Gosain et al., 2006; Schuol et al., 2008a, 2008b]. The model was developed to quantify the impact of land management practices on water, sediment, and crop yield in large complex watersheds with varying soils, land uses, and management conditions over long periods of time. The main components of SWAT are hydrology, climate, nutrient cycling, soil temperature, sediment movement, crop growth, agricultural management, and pesticide dynamics. In this study, we used Arc-SWAT [Olivera et al., 2006], where the ArcGIS (version 9.1) environment is used for project development.

[12] Spatial parameterization of the SWAT model is performed by dividing a watershed into subbasins based on topography, soil, land use, and slope. The resulting units, referred to as hydrologic response units (HRUs), are used as the basis of the water balance calculation. Water, sediment, 
and nutrient transformations and losses are determined for each HRU, aggregated at the subbasin level, and then routed to the associated reach and catchment outlet through the channel network. SWAT represents the local water balance through four storage volumes: snow, soil profile $(0-2 \mathrm{~m})$, shallow aquifer $(2-20 \mathrm{~m})$, and deep aquifer $(>20 \mathrm{~m})$. The soil water balance equation is the basis of hydrological modeling. The simulated processes include surface runoff, infiltration, evaporation, plant water uptake, lateral flow, and percolation to shallow and deep aquifers. Surface runoff is estimated by a modified Soil Conservation Service curve number equation using the daily precipitation data based on soil hydrologic group, land use and land cover characteristics, and antecedent soil moisture.

[13] In this study, potential evapotranspiration (PET) was simulated using Hargreaves method [Hargreaves and Samani, 1985]. Actual evapotranspiration (AET) was determined based on the methodology developed by Ritchie [1972]. The daily value of the leaf area index (LAI) was used to partition the PET into potential soil evaporation and potential plant transpiration. LAI and root development were simulated using the "crop growth" component of SWAT, which is a simplified version of the erosion productivity impact calculator (EPIC) crop model [Williams et al., 1984]. This component represents the interrelation between vegetation and hydrologic balance. Plant growth was determined from leaf area development, light interception, and conversion of intercepted light into biomass assuming a plant species-specific radiation use efficiency. Phenological plant development was based on daily accumulated heat units, potential biomass, and harvest index. The harvest index is the fraction of aboveground plant dry biomass that is used as dry economic yield to calculate crop yield. Plant growth can be inhibited by user-specified temperature, water, nitrogen, and phosphorus stress factors. A more detailed description of the model is given by Neitsch et al. [2002].

\subsection{Future Climate Data and Model Scenarios}

[14] Global climate models, also known as general circulation models (GCMs), numerically simulate changes in climate as a result of slow changes in some boundary conditions (such as the solar constant) or physical parameters (such as the greenhouse gas concentration). In this study, we used outputs of the Canadian Global Coupled Model (CGCM 3.1) version T63, which has a surface grid with a spatial resolution of roughly $2.8^{\circ}$ latitude/longitude and 31 levels in the vertical. With this resolution 37 grid points fell inside Iran.

[15] GCMs contain significant uncertainties and IPCC [2007] recommends that the results of different models and scenarios should be considered in climate change studies. It has become standard practice to use several climate scenarios to characterize uncertainty in future climate [Arnell et al., 2004]. In a hydrological impact study of climate change, the most important sources of uncertainty may arise from, in decreasing order, the emission scenarios [Arnell et al., 2004], climate model parameterization (particularly for precipitation), downscaling [Wilby and Harris, 2006], and the hydrological model parameterization [Wilby and Harris, 2006; Caballero et al., 2007]. In this work, we use three commonly used scenarios, A1B, B1, and A2, from the widely used Canadian Global Coupled Model (CGCM 3.1). Results from the CGCM appear prominently in several chapters in the
IPCC report [IPCC, 2007, chapters 8-12] and form the basis of a variety of studies of climate change.

[16] As GCMs are global models, they do not have suitable resolution for hydrologic modeling. Hence they need to be downscaled to acceptable resolutions. Popular methods include change factor (CF) methodology whereby future changes in climate projected by GCMs are applied to a baseline climatology, and statistical downscaling methods where statistical transfer functions are used to estimate point-scale meteorological series [Diaz-Nieto and Wilby, 2005].

[17] Within the CGCM we analyzed three commonly used scenarios: A1B, A2, and B1. The families of A1 scenario describe a future world of increasing globalization and rapid but uniform global economic and technological growth with increasing materialistic and consumerist tendencies. The A1B scenario in this family depicts a world with a balanced use of fossil and nonfossil fuel as a main energy source. The A2 scenario describes a heterogeneous world with rapid but diverse regional economic and technological growth and increasing materialistic and consumerist tendencies. The B1 scenario highlights an increasing global cooperation and convergence with more priority given to environmental problems in the form of developing cleaner and more efficient technologies.

[18] A key aspect of the climate change impact study is the spatial and temporal downscaling of the GCM results. In this study, the CGCM data were downscaled using the nearest observation station for the period of 1980-2002 in Iran. For rainfall, we used a simple ratio method where for each month we divided the average CGCM data by the observed data and multiplied the daily CGCM data by this factor to obtain future daily rainfall data.

[19] For the temperature we tested linear and nonlinear models as used in the literature [Wilby et al., 1998] and chose a fourth-degree regression model based on the calibration $(\sim 1990-2000)$ and validation $(\sim 1982-1989)$ results of stations in different regions. In general, the results of a first-degree linear and a fourth-degree nonlinear model were similar except for small and large temperature values, where the nonlinear model performed systematically better, especially for the validation data set. Hence we opted for the nonlinear model.

\subsection{Model Inputs and Model Setup}

[20] Data required for this study were compiled from different sources. They include the following: Digital elevation model (DEM) data were extracted from the global U.S. Geological Survey's (USGS) public domain geographic database HYDRO1k with a spatial resolution of $1 \mathrm{~km}$ (http:// edc.usgs.gov/products/elevation/gtopo30/hydro/index. html). The land cover map was from the USGS Global Land Use Land-Cover Characterization (GLCC) database with a spatial resolution of $1 \mathrm{~km}$, which distinguish 24 land use and land cover classes (http://edcsns17.cr.usgs.gov/glcc/glcc. html). The soil map was obtained from the global soil map of the Food and Agriculture Organization of the United Nations (FAO) [FAO, 1995], which provides data for 5000 soil types comprising two layers $(0-30 \mathrm{~cm}$ and $30-$ $100 \mathrm{~cm}$ depth) at a spatial resolution of $10 \mathrm{~km}$. Information about the digital stream network, administrative boundaries depicting country and province boundaries, and reservoirs/ dams was available from the National Cartographic Center 
of Iran, which provides information at a spatial resolution of $1 \mathrm{~km}$.

[21] Weather input data (daily precipitation, maximum and minimum temperature, daily solar radiation) were obtained from the Public Weather Service of the Iranian Meteorological Organization (WSIMO) for 37 synoptic stations nearest to the CGCM's grid data. The weather data for each subbasin are assigned automatically in SWAT using the closest weather station. River discharge data required for calibration-validation were obtained from Ministry of Energy (MOE) of Iran for about 60 hydrometric stations for the period 1980-2002. Historical records on annual yield and area cultivated with irrigated wheat were obtained for the period 1980-2002 from the Agricultural Statistics and the Information Center of Ministry of Jahade-Agriculture and Statistical Center of Iran.

\subsection{Calibration Setup and Analysis}

[22] In this study we recalibrated the model of Faramarzi et al. [2009] by removing the dams and irrigated agriculture, and subsequently the stations that were affected by the dams. This was necessary as future land use changes and dam operation could not be predicted with any accuracy. The spatial discretization resulted in 506 subbasins using dominant soil and land use option. The hydrologic SWAT model was calibrated and validated at the subbasin level based on daily observed discharges at 60 stations across the country (Figure 1), and annual winter wheat yields at representative subbasins in each province. The combination of river discharge and crop yield in the objective function provides a more reliable estimate of both runoff and evapotranspiration and hence soil moisture and deep aquifer recharge. For details of the procedures for calibration, validation, sensitivity analysis, and uncertainty analysis we refer the readers to Faramarzi et al. [2009]. Some essential detail is provided below.

[23] The SUFI-2 [Abbaspour et al., 2007] algorithm in the SWAT-CUP program [Abbaspour, 2007] was used for parameter optimization. In this algorithm all uncertainties (parameter, conceptual model, input, etc.) are mapped onto the parameter ranges as the procedure tries to capture most of the measured data within the $95 \%$ prediction uncertainty. The overall uncertainty in the output is quantified by the $95 \%$ prediction uncertainty (95PPU) calculated at the $2.5 \%$ and $97.5 \%$ levels of the cumulative distribution of an output variable obtained through Latin hypercube sampling. Two indices are used to quantify the goodness of calibration/ uncertainty performance, the $P$-factor, which is the percentage of data bracketed by the 95PPU band (maximum value $100 \%$ ), and the $R$-factor, which is the average width of the band divided by the standard deviation of the corresponding measured variable. Ideally, we would like to bracket most of the measured data (plus their uncertainties) within the 95PPU band ( $P$-factor $\rightarrow 1$ ) while having the narrowest band $(R$-factor $\rightarrow 0)$. (More details on the SUFI-2 procedure are given by Abbaspour et al. [2007], Schuol et al. [2008a, 2008b], and Yang et al. [2008].)

[24] In order to compare the measured and simulated monthly discharges we used the following criterion modified from Krause et al. [2005]:

$$
\Phi=\left\{\begin{array}{lll}
|b| R^{2} & \text { for } & 0<|b| \leq 1 \\
|b|^{-1} R^{2} & \text { for } & |b|>1
\end{array}\right.
$$

where $R^{2}$ is the coefficient of determination between the measured and simulated signals and $b$ is the slope of the regression line. For multiple discharge stations, the objective function was simply an average of $\Phi$ for all stations within a region of interest:

$$
g=\frac{1}{n} \sum_{i=1}^{n} \Phi_{i}
$$

where $n$ is the number of stations. The function $\Phi$ varies between 0 and 1 . Therefore the objective function, unlike, for example, Nash-Sutcliffe, is not dominated by one or a few badly simulated stations.

\section{Results and Discussions}

\subsection{Downscaling Climate Variables}

[25] The downscaled temperature data from CGCM agreed quite well with the recorded historical data. All 37 stations had $R^{2}$ values in the range of $0.92-1.00$. The fit of the downscaled rainfall data was also relatively good as compared with the measured historical data. Figures $3 \mathrm{a}$ and $3 \mathrm{~b}$ show the cumulative probability distribution of rainfall for the historic (1980-2002) and the CGCM data for a wet station in Gilan province near the Caspian Sea and a dry station in Esfahan province, central Iran. As shown in Figure $3 \mathrm{a}$, in the wet region, smaller rainfalls (especially $\leq 2 \mathrm{~mm} \mathrm{~d}^{-1}$ ) are slightly underestimated by CGCM, while in the dry region (Figure 3b) CGCM slightly overestimates intermediate to large rainfall events. In Figures $3 c$ and $3 d$ the predicted long-term average precipitations $\left(\mathrm{mm} \mathrm{d}^{-1}\right)$ are compared with the historical data for different scenarios in different time periods. As shown, major changes in the wet region occur in the fall season, while in the dry region, all seasons except summer experience some change. Figures $3 \mathrm{e}$ and $3 \mathrm{f}$ show average monthly changes in maximum temperature of wet and dry regions, respectively. Maximum temperature varies between $1^{\circ}$ and $5^{\circ}$ in different scenarios with the highest occurring in July in the dry region for A2 scenario during the period 2070-2100.

\subsection{Hydrological Model Calibration and Uncertainty Analysis}

[26] The hydrologic model of Iran was calibrated for the period of 1982-1992 and validated for 1993-2002. Model performance was quite satisfactory across the country with the worst results being obtained in areas of intense water management. Figure 4 illustrates calibration results for two better simulated stations from the wet and dry regions of the country. The shaded regions indicate the $95 \%$ prediction uncertainty (95PPU). In the wet region, the uncertainties are generally large as indicated by the $R$-factor (i.e., the average thickness of the 95PPU band divided by the standard deviation of the measured data; on the basis of our experience, a value close to 1 would be satisfactory), but there are a larger number of measured data bracketed by the 95PPU as indicated by the $P$-factor (i.e., percent data falling in the 95PPU band) signifying a more reliable model. In the dry region, model prediction uncertainty is smaller compared with the wet region but still larger than desired. The large uncertainties are partly due to the lack of information in water management such as existence of reservoirs and regional 
(a) Ramsar Station in a wet region of Iran (1980-2000)

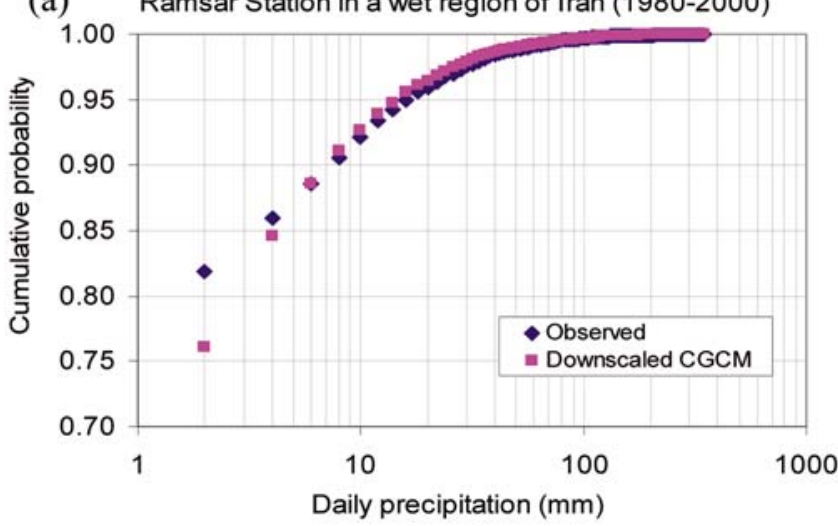

(c)

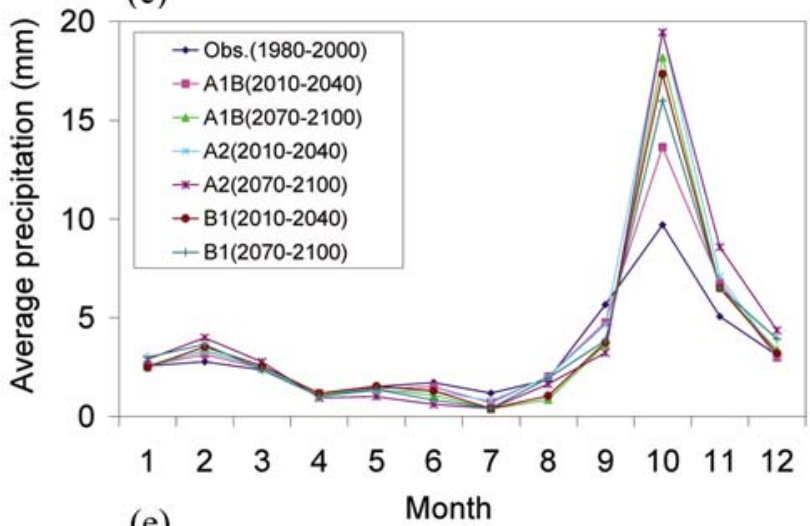

(e)

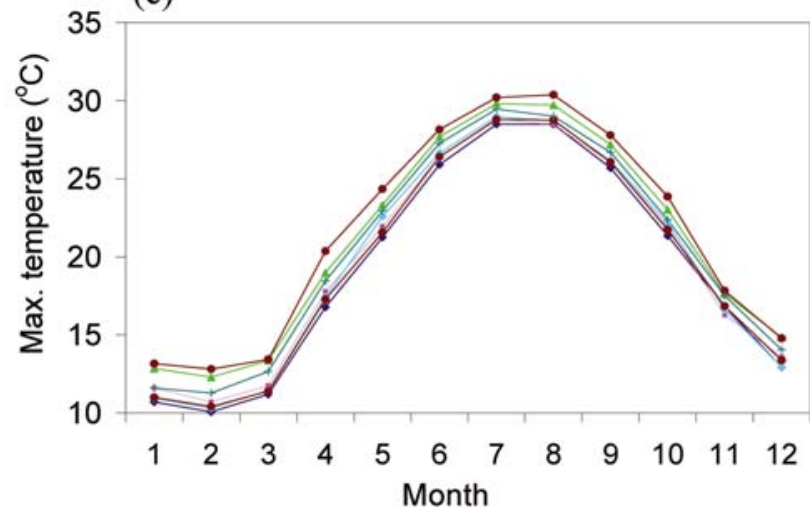

(b) Khoor-biabanak Station in a Dry region of Iran (1980-2000)

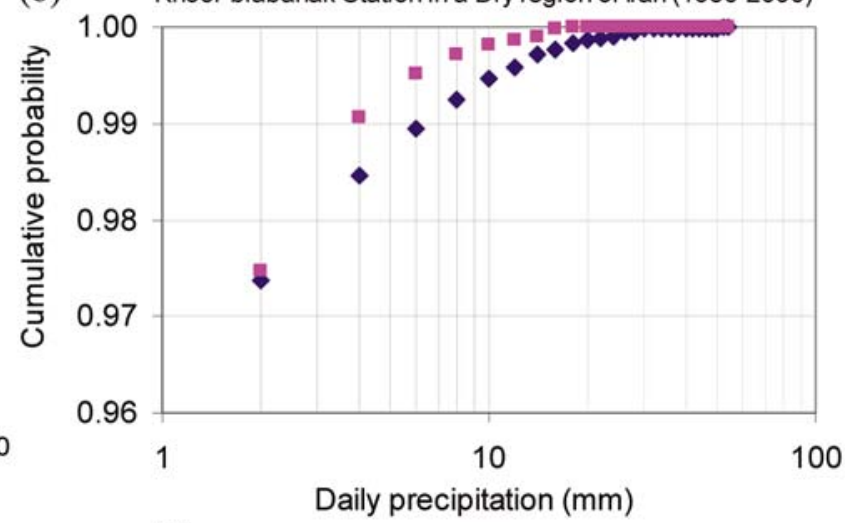

(d)

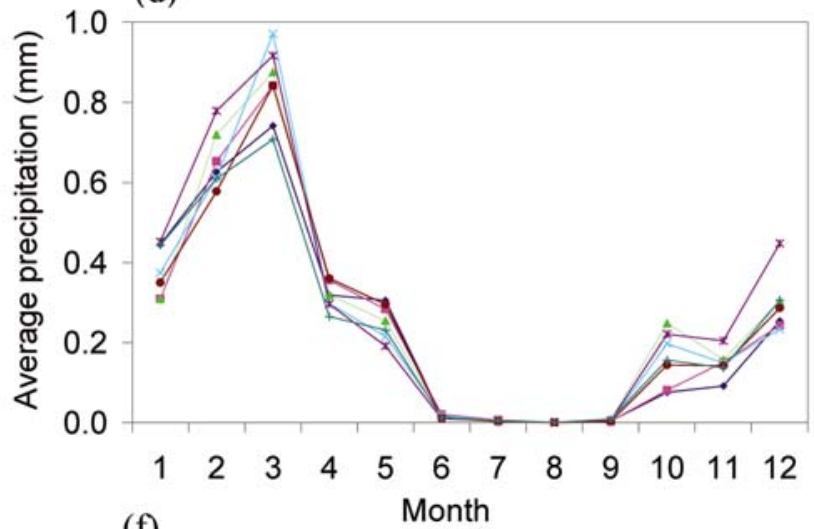

(f)

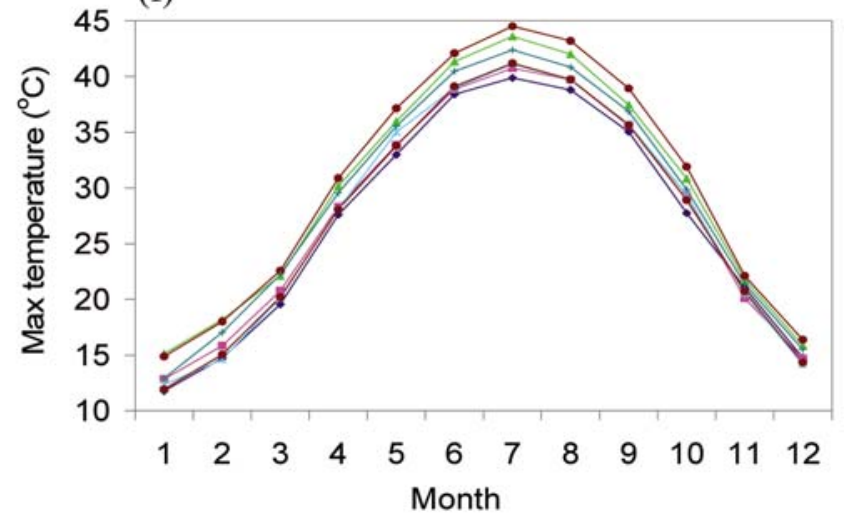

Figure 3. Comparison of the downscaled precipitation (scenario A1B) in a wet (Figure 3a) and dry (Figure $3 \mathrm{~b}$ ) region of the country. Figures $3 \mathrm{c}$ and $3 \mathrm{~d}$ compare average observed precipitation in each month for the same two stations with the three different scenarios and two time periods. Figures $3 \mathrm{e}$ and $3 \mathrm{f}$ compare maximum temperatures for the different scenarios.

water transfer [Faramarzi et al., 2009]. The $R^{2}$ and NashSutcliffe (NS) coefficient, calculated between the best simulation (simulation with the largest objective function value) and the measured data, indicate quite satisfactory results for both regions. Similar results were obtained for model validation not shown here. For all stations, $R^{2}$ ranged between 0.1 and 0.8 for calibration and validation results.

\subsection{Impact of Climate Change on Precipitation Distribution}

[27] In Figure 5, the historic precipitation distribution (Figure 5a) and the anomaly maps (maps of percent deviation from historic data) are shown for the whole country for different scenarios. The differences are calculated between the averages of (2013-2039) and (2073-2099) periods with those of the (1980-2002) period. While all scenarios show an increase in the precipitation in the northern and western parts of the country, there are major differences in the southern and eastern parts. The increases in the precipitation in the northern parts could be quite large, even as large as $40 \%$. Prediction of rainfall in scenario A2 (Figure $5 \mathrm{~b}$ ) is exceptionally large for most of the country during 20732099. On the basis of CGCM, the southeastern part of the country could experience up to a $40 \%$ decrease in precipitation in all scenarios. As precipitation is already small in this part of the country, the predicted decreases may have a 

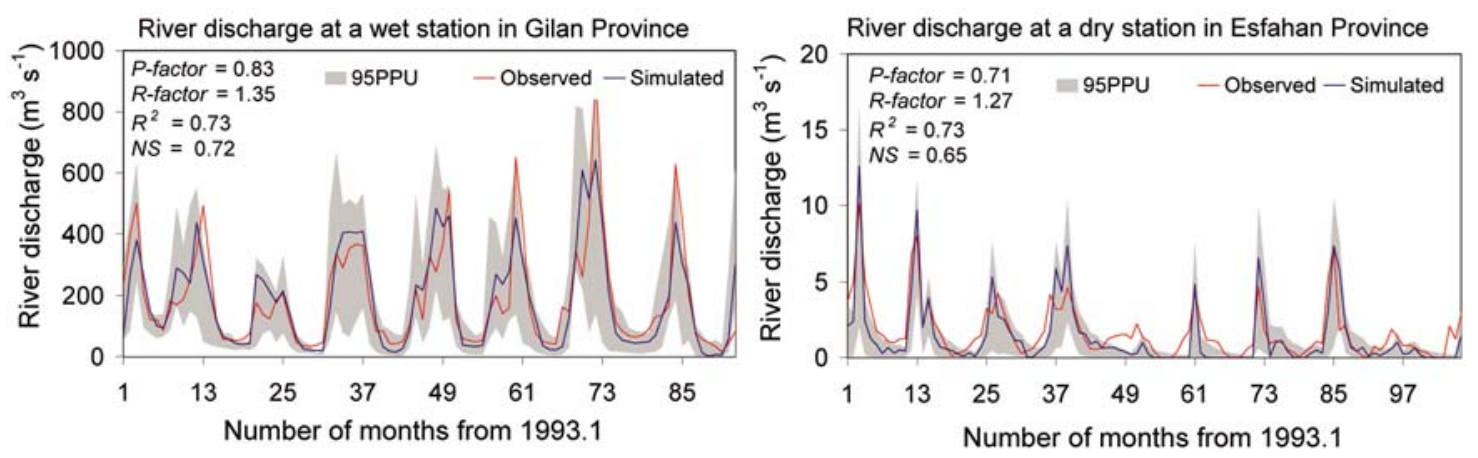

Figure 4. Results of Soil and Water Assessment Tool (SWAT) calibration for two selected hydrometric stations in the wet northern and dry southern regions of the country.

significant effect on increasing droughts and hence crop production in this region, as discussed in section 3.6.

\subsection{Impact of Climate Change on Blue and Green Water}

[28] Currently, the definition of "blue water" is generally accepted as "the sum of the river discharge and the deep groundwater recharge." This is in essence the water resources by the traditional hydrological and engineering definition. There exist slightly different definitions for the term "green water." Falkenmark and Rockstrom [2006] differentiate between the green water "resource" and the green water "flow." According to their definition, "green water resource is the moisture in the soil," which is a renewable resource and can potentially generate economic returns, as it is the source for rain-fed agriculture. The green water flow is composed of the actual evaporation (the nonproductive part) and the actual transpiration (the productive part), commonly referred to together as the actual evapotranspiration. Using SWAT, we could distinguish the two different water resources components and study the effect of climate change on each component. Figure 6 shows the average values of blue water $\left(\mathrm{mm} \mathrm{yr}^{-1}\right.$ ) based on the historic data of 1980-2002 (Figure 6a) as well as the anomaly graphs for scenario B1 and A1B for periods 2013-2039 and 2073-2099 and scenario A2 for the period 2073-2099 as it is an extreme case. Generally, the blue water resources decrease from north to south and west to east. The near-future simulations show an increase in blue water resources in the western half of the country while the central and eastern half experience a reduction in the already small water resources. In the far future, scenario A2 shows most of the country enjoying an increase in the blue water resources (Figure 6b). It should be noted, however, that an increase of $>300 \%$ in the eastern regions of the country amounts to blue water resources of about $75 \mathrm{~mm} \mathrm{yr}^{-1}$, which is still quite meager in the water resource sense but could have a substantial impact on the ecosystem of this desert region.

[29] In the calculation of actual evapotranspiration, soil moisture, and groundwater recharge (maps not shown), we assumed that the land cover in the future will stay the same as the period of 1980-2002. Hence our results simply provide an indication of future changes rather than an actual scenario. As temperature increases, actual evapotranspiration (or green water flow) is also expected to increase if there is enough water in the soil. Our calculations show AET slightly decreasing in large parts of the country in the north and west. This is because of the assumption that land use and land cover do not change; hence as $\mathrm{CO}_{2}$ increases, a smaller amount of water is needed to produce a target yield. In reality, as $\mathrm{CO}_{2}$ and temperature increase, there will be a denser vegetation cover and a larger actual transpiration. This observation highlights that prediction of future land use/land cover is an important but difficult problem in climate change studies.

[30] All scenarios predict an increase in soil moisture for most regions of the country. We believe the future soil moisture is overestimated for the same reason that evapotranspiration is underestimated as discussed above.

[31] Figure 7 shows the blue water resources and the green water flow aggregated at provincial level for four dry (Figure 7, right) and wet (Figure 7, left) provinces. These provinces were selected because they represent both climatic extremes and important agricultural production regions (see Figure 1 for the location of the provinces). In Figure 7, the hydrologic model uncertainties (size of the blue and yellow bars) are compared with the predictions of the three climate change scenarios (different columns). Figure 7 was produced to highlight two points. First, the large differences in blue and green water flow between different scenarios more or less disappear when data are aggregated from subbasin to provincial level. This indicates the dependence of uncertainty analysis on the scale of the study [see also Schuol et al., 2008b]. Second, it appears that there is a greater uncertainty in the hydrological model results than the predictions of different climatic scenarios at the provincial scale. This is contrary to the remarks of Caballero et al. [2007], which puts the major sources of uncertainty in decreasing order as emission scenarios, climate model parameterization, downscaling, and finally the hydrologic model parameterization. The order of uncertainty is perhaps dependent on the scale of the study, with hydrologic model uncertainty becoming larger and the difference in emission scenario becoming smaller as the scale of study increases. It would perhaps be interesting to compare the outcome of different climate models for this part of the world. This analysis was not done in this study due to time constraints.

\subsection{Impact of Climate Change on Deep Aquifer Recharge}

[32] Calculation of aquifer recharge indicated that eastern half of the country will see decreases of up to $50-100 \%$ in groundwater recharge in regions that are already scarce in water resources. The northwestern part of the country will 

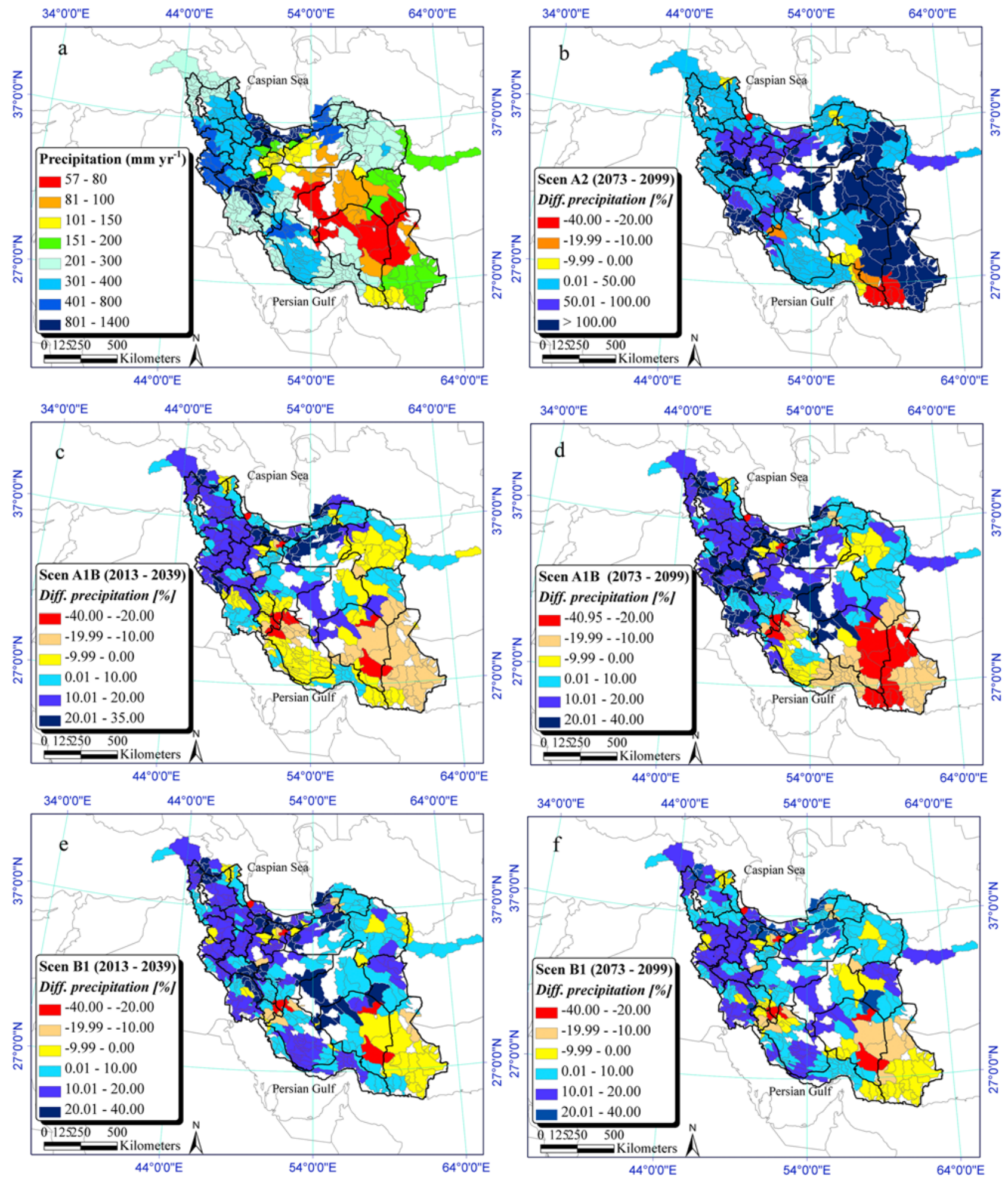

Figure 5. The anomaly map of precipitation averages. Figure 5a shows the historic precipitation distribution. The \% differences are calculated based on the averages of data periods 2013-2039 and 2073-2099 from the average of 1980-2002.

see an increase in groundwater recharge due to an increase in rainfalls. All scenarios in the far future, as well as B1 scenario for the near future, indicate an increase in the aquifer recharge in this region. As discussed above with respect to green water flow, recharge could be overestimated due to holding land cover constant in the model.

\subsection{Impact of Climate Change on Flooding and Drought}

[33] Figure 8 shows the average distribution of the number of wet days (precipitation $\geq 2 \mathrm{~mm} \mathrm{~d}^{-1}$ ) at four wet provinces in northern parts of the country for the historic (1980-2002) and the near future (2013-2039) scenarios. All 

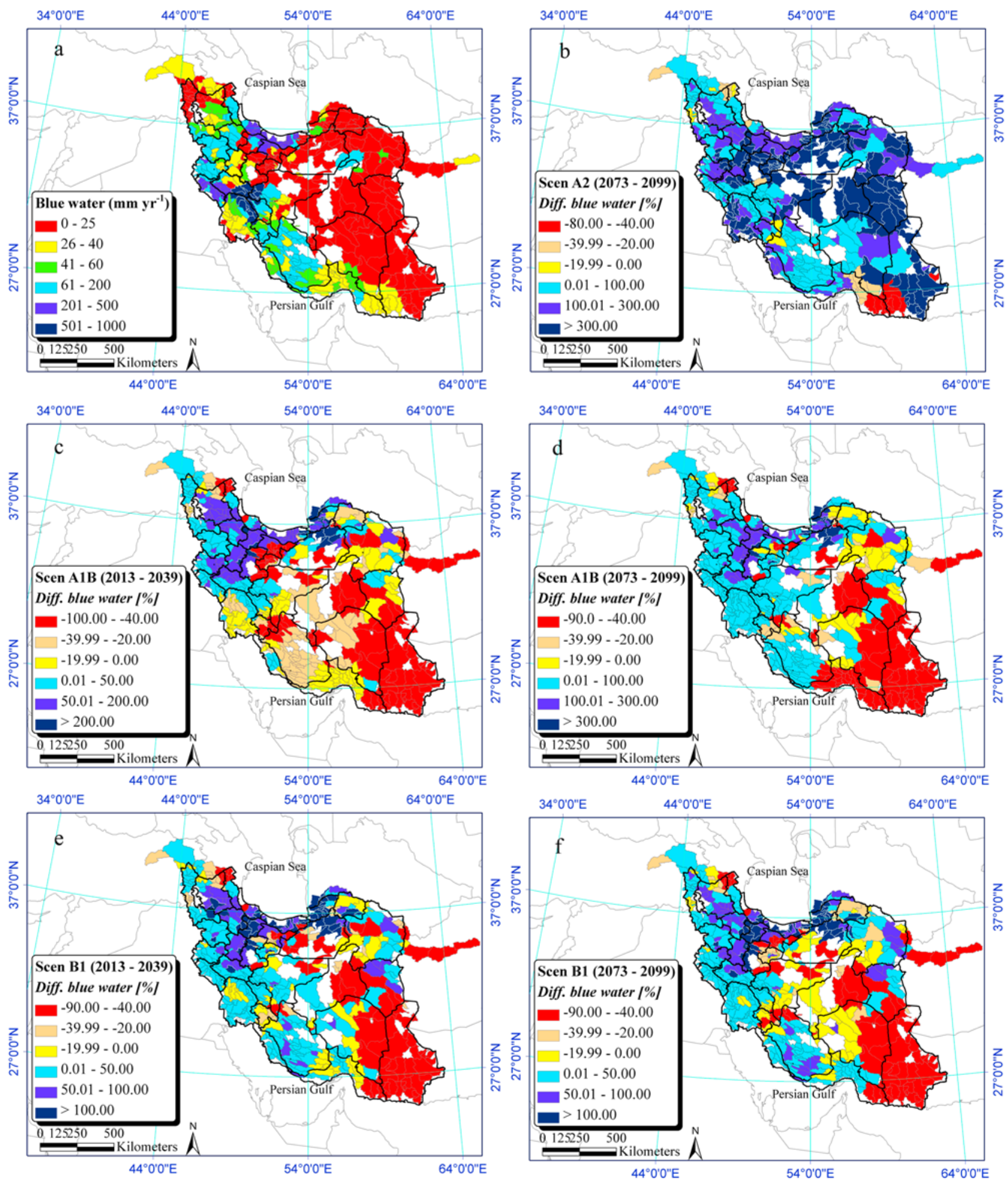

Figure 6. Showing the effect of climate change on the blue water resources of the country. (a) Historic absolute values. (b) Blue water anomaly based on scenario A2 for the period of 2073-2099. (c) Blue water anomaly based on scenario A1B for the period of 2013-2039. (d) Results of scenario A1B for the period of 2073-2099. (e) Blue water anomaly based on scenario B1 for the period of 2013-2039.

(f) Results of scenario B1 for the period of 2073-2099.

four provinces show an increase in the number of days where rainfall $\geq 2 \mathrm{~mm}$, except for the summer months. Khorasan (a province at the border of wet and dry region) shows a decrease in winter but a moderate increase in summer rainfall, a shift which should have a positive effect on rain-fed crop production in this province. Figure 9 and Figure 10 illustrate the number of days where the rainfall is $\geq 10 \mathrm{~mm}$ and $\geq 50 \mathrm{~mm}$, respectively. Major increases are seen in the fall 

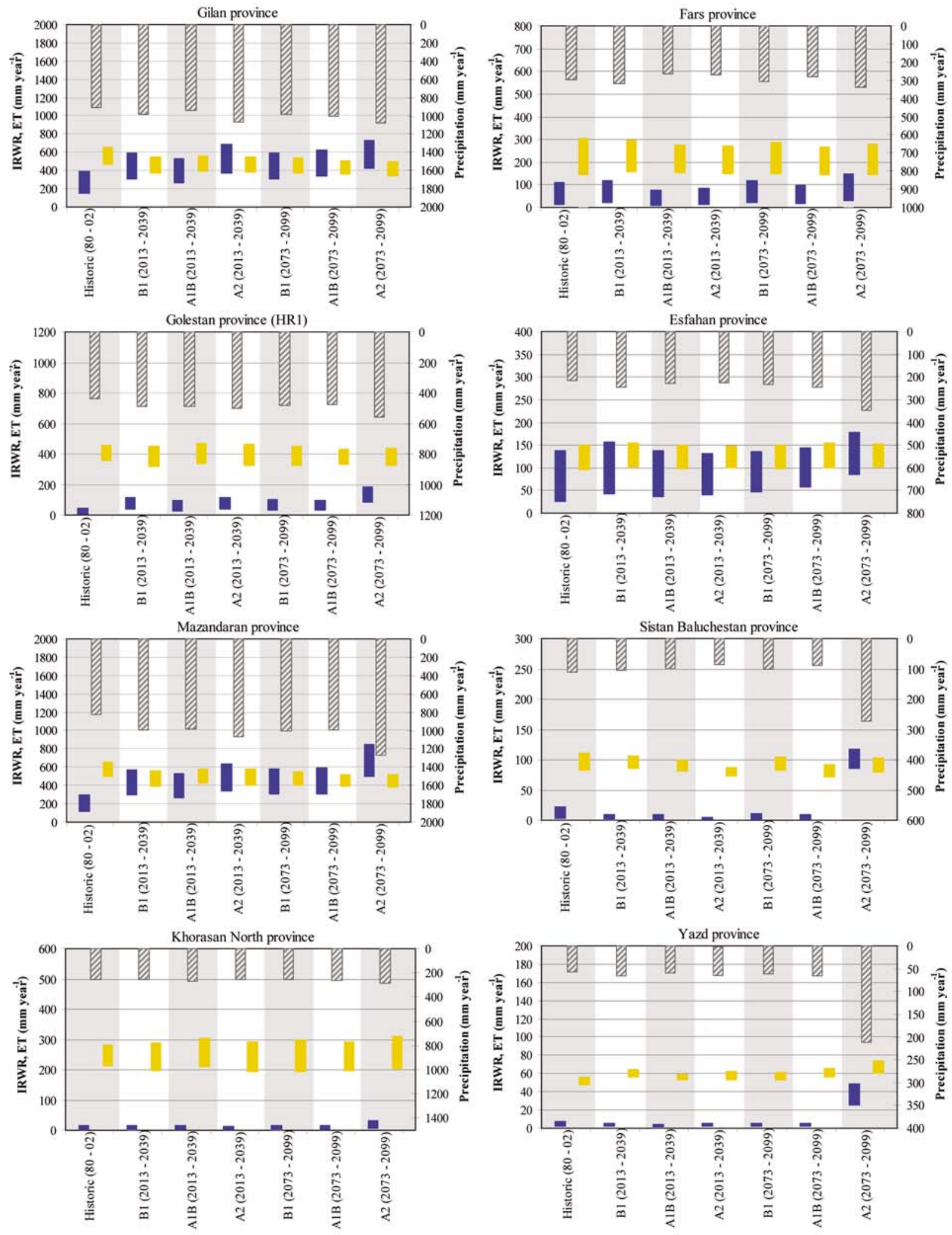

95PPU Blue water (IRWR)

- 95PPU Actual ET

巴 Precipitation

Figure 7. Blue water resources and green water flow aggregated at provincial level. The figure compares the hydrologic model uncertainties (size of blue and yellow bars) to the differences in climate scenarios (different columns). 
Wet provinces (2013-2039) (Number of days with precipitation $\geq 2 \mathrm{mmday}^{-1}$ )
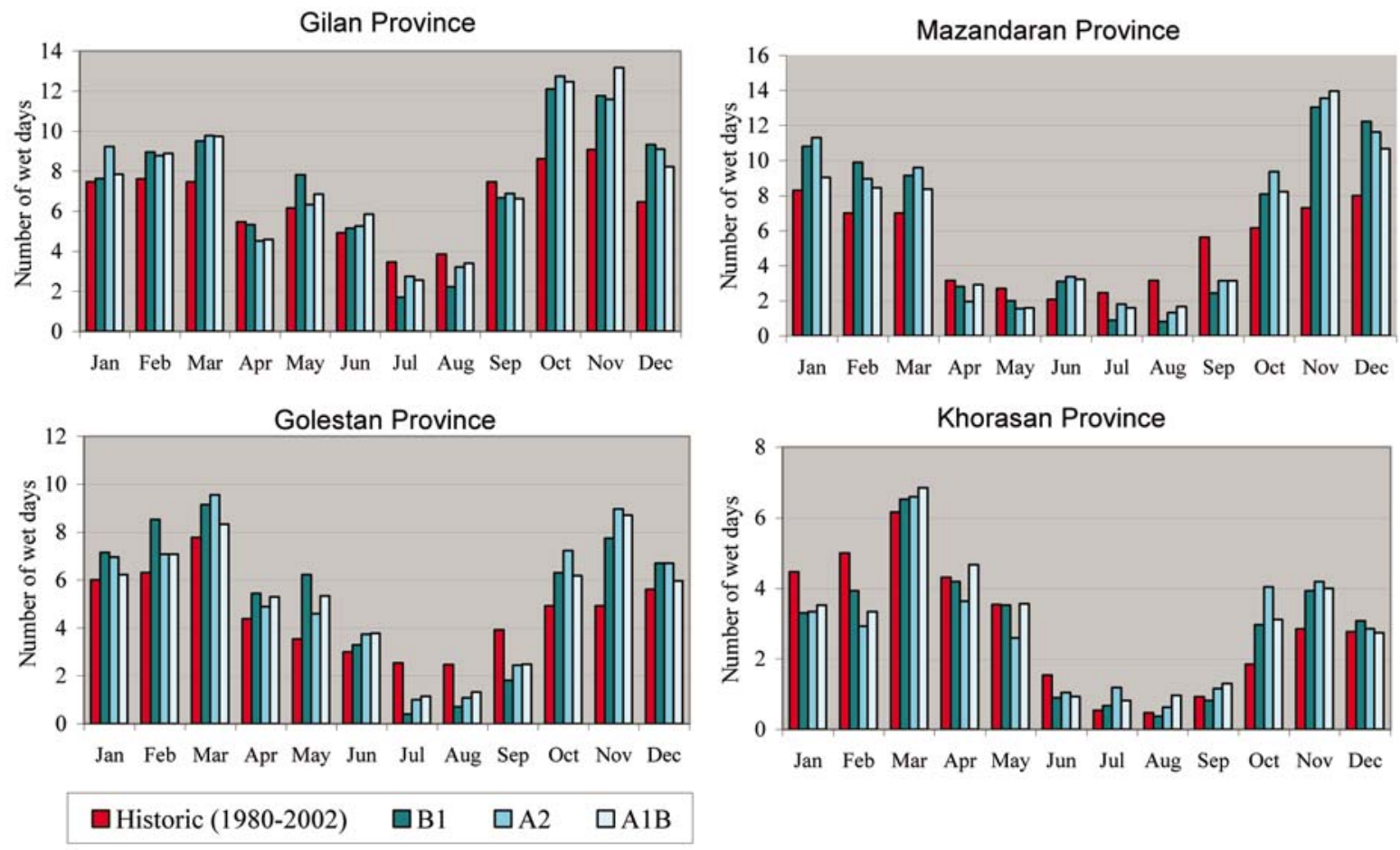

Figure 8. Comparison of the number of wet days between historic and future climate conditions in wet regions of the country. In these graphs a wet day is defined as a day with precipitation $\geq 2 \mathrm{~mm}$.
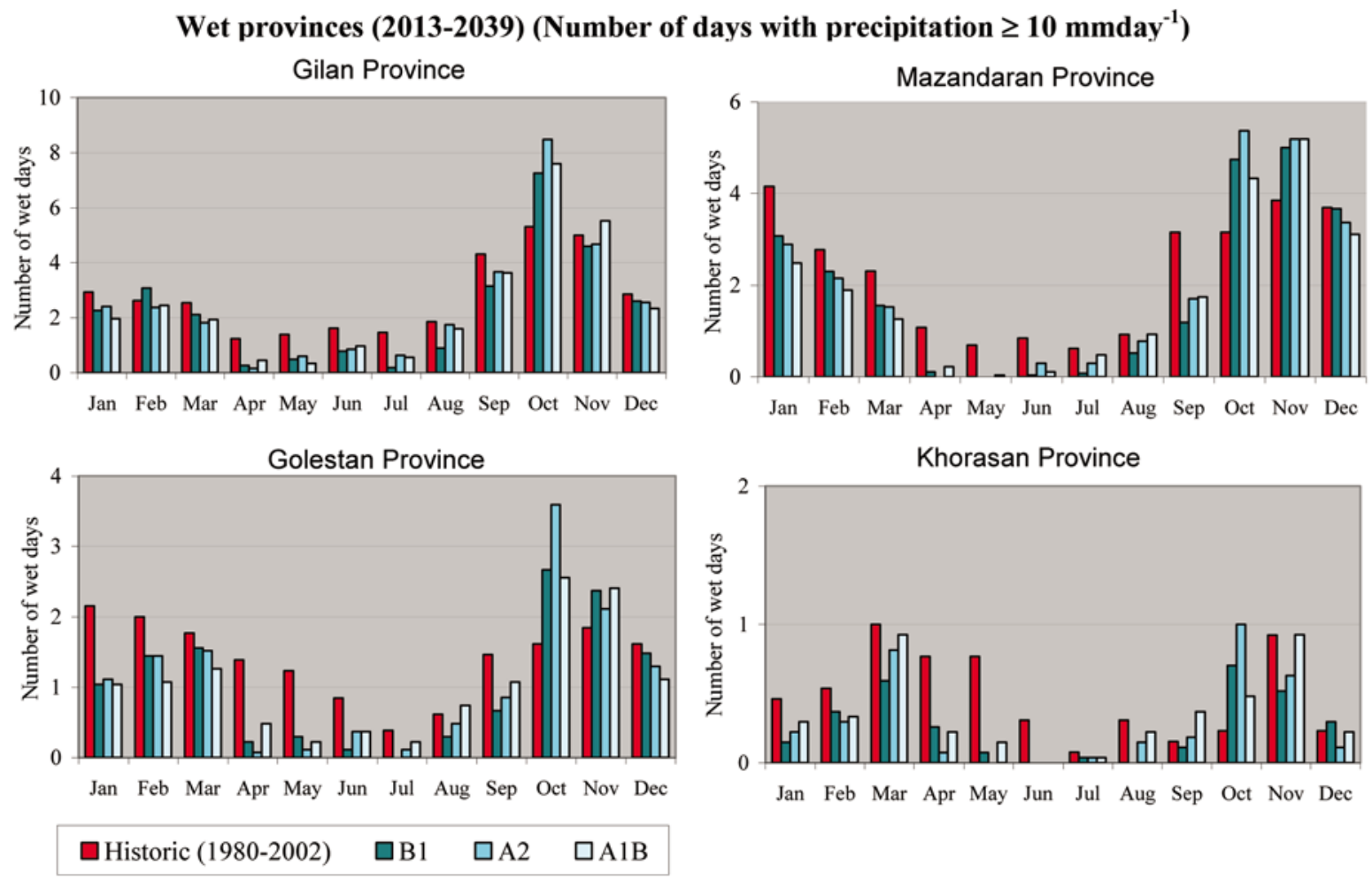

Figure 9. Comparison of the number of wet days between historic and future climate conditions in wet regions of the country. In these graphs a wet day is defined as a day with precipitation $\geq 10 \mathrm{~mm}$. 


\section{Wet provinces (2013-2039) (Number of days with precipitation $\geq 50 \mathrm{~mm} \mathrm{day}^{-1}$ )}
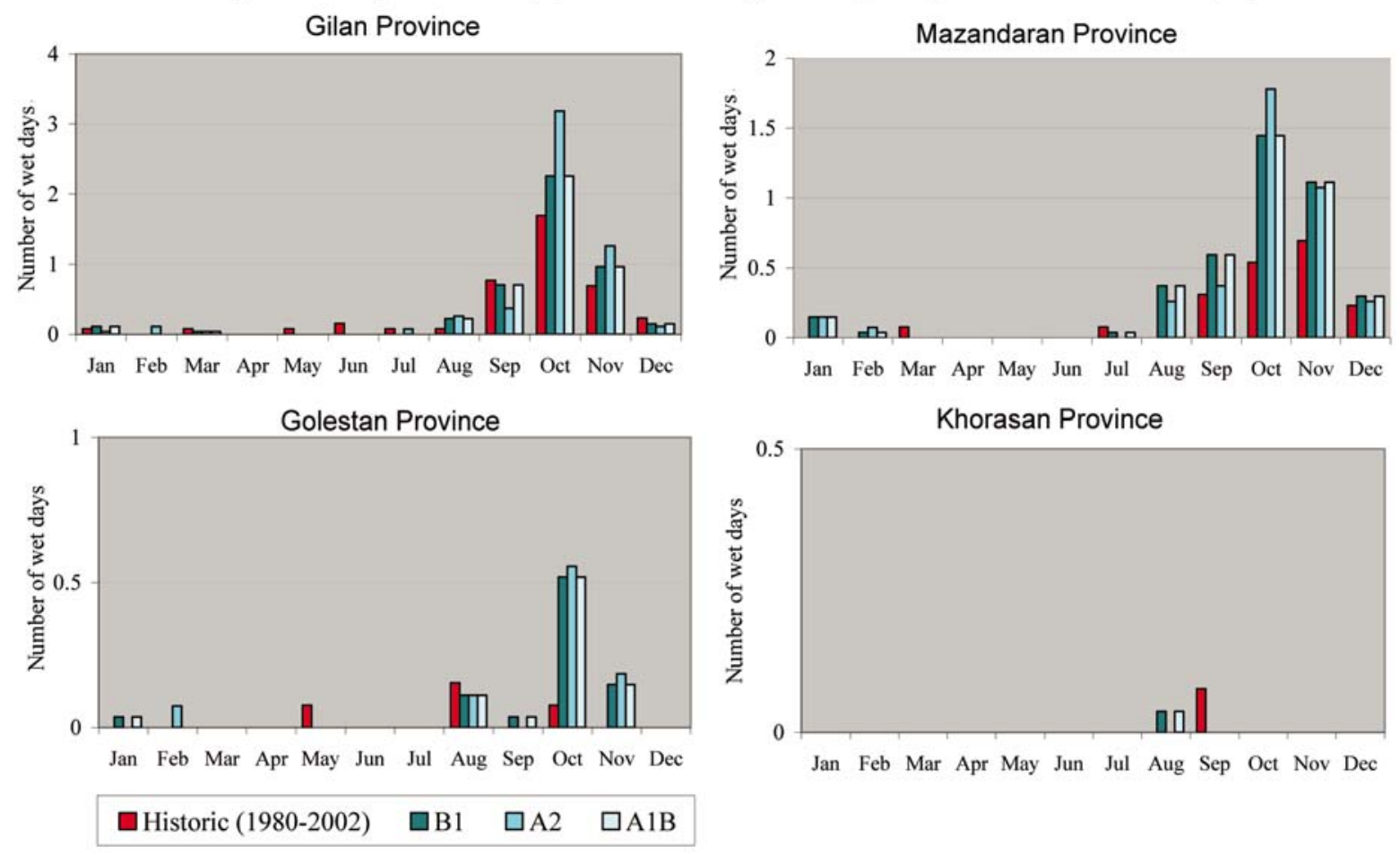

Figure 10. Comparison of the number of wet days between historic and future climate conditions in wet regions of the country. In these graphs a wet day is defined as a day with precipitation $\geq 50 \mathrm{~mm}$.

Dry provinces (2013-2039) (Number of days with precipitation $\geq 2 \mathrm{mmday}^{-1}$ )
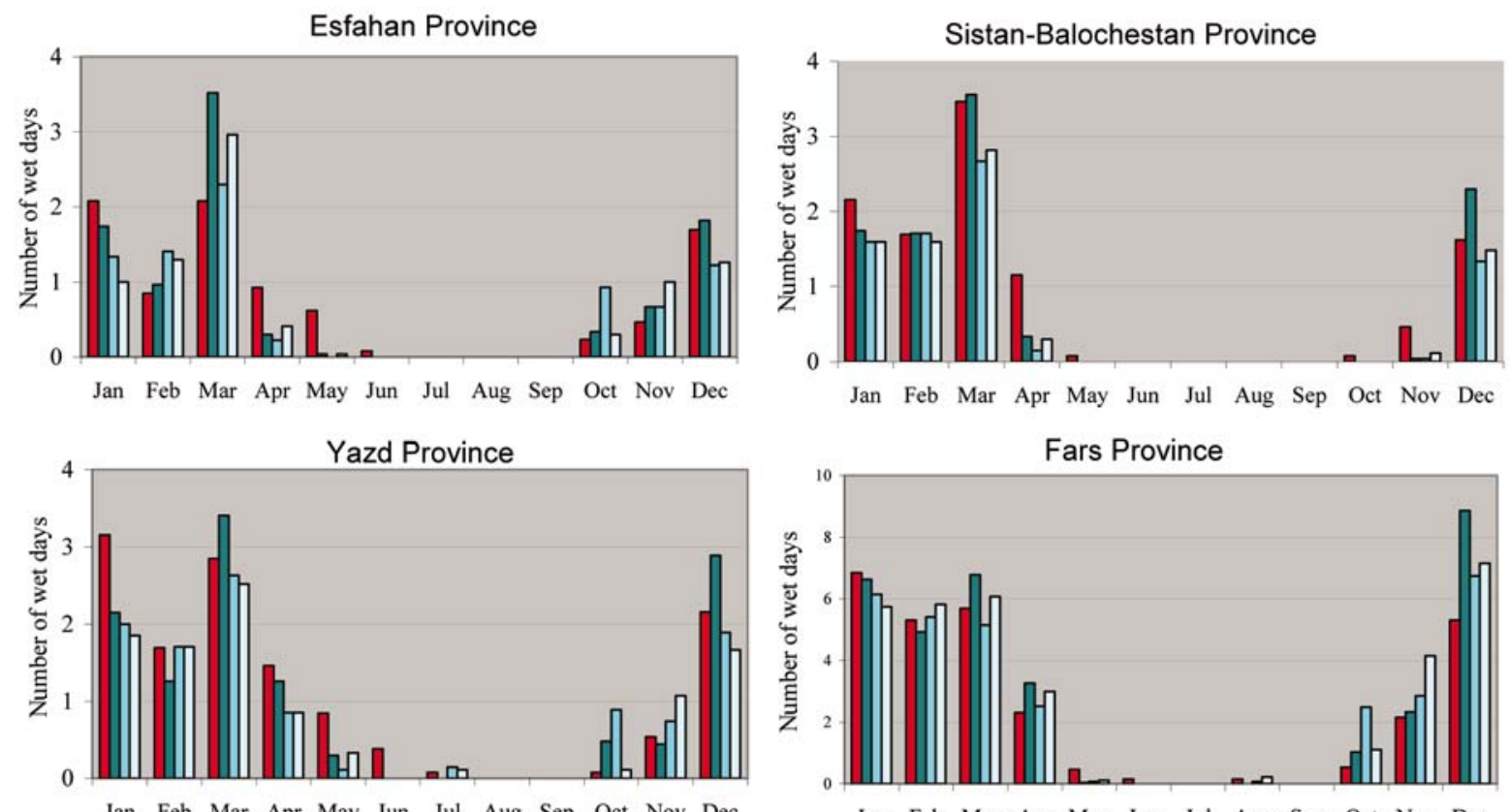

Jan Feb Mar Apr May Jun Jul Aug Sep Oct Nov Dec

Jan Feb Mar Apr May Jun Jul Aug Sep Oct Nov Dec

$\square$ Historic (1980-2002) $\square \mathrm{B} 1 \quad \square \mathrm{A} 2 \quad \square \mathrm{A} 1 \mathrm{~B}$

Figure 11. Comparison of the number of wet days between historic and future climate conditions in dry regions of the country. In these graphs a wet day is defined as a day with precipitation $\geq 2 \mathrm{~mm}$. 


\section{Dry provinces (2013-2039) (Number of days with precipitation $\geq 10$ mmday $^{-1}$ )}
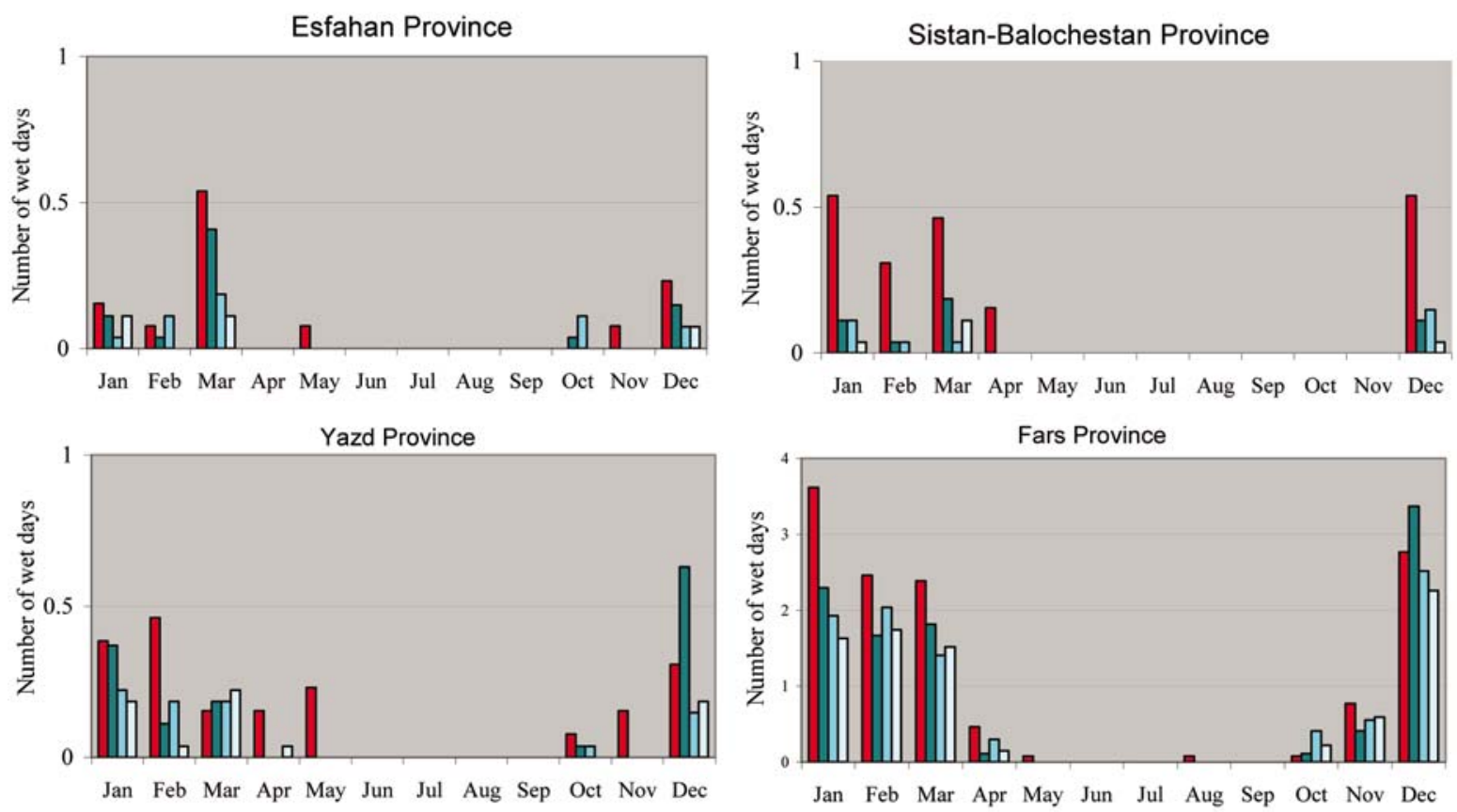

Jan Feb Mar Apr May Jun Jul Aug Sep Oct Nov Dec

$\square$ Historic (1980-2002) $\quad \square \mathrm{B} 1 \quad \square \mathrm{A} 2 \quad \square \mathrm{A} 1 \mathrm{~B}$

Figure 12. Comparison of the number of wet days between historic and future climate conditions in dry regions of the country. In these graphs a wet day is defined as a day with precipitation $\geq 10 \mathrm{~mm}$.

months, indicating the possibility of larger and more frequent floods in the wet regions of the county. In Figure 10, there is a sharp increase in the number of days where precipitation is $>50 \mathrm{~mm}$ in October and November.

[34] Figure 11 shows the average number of wet days where rainfall is $\geq 2 \mathrm{~mm} \mathrm{~d}^{-1}$ for four dry provinces in the central and southern part of the country. The results are different for each province from month to month and between different scenarios. In Esfahan and Yazd, there is a reduction in late spring rainfall with an increase in early fall months. This shift will have important adverse consequences in crop production. In Sistan-Baluchestan both spring and fall experience fewer rainfall events, while Fars sees a general increase in the rainfall. Figure 12 shows the number of days where rainfall is $\geq 10 \mathrm{~mm}$ in the dry regions. The sharp reductions in the number of days with large rainfall events throughout the year will have significant consequences for water resources of these and similar provinces in dry regions of the country. Except for a few times in Fars, other dry provinces did not have any occurrences of rainfall $\geq 50 \mathrm{~mm} \mathrm{~d}^{-1}$.

[35] In a further analysis, we plotted in Figure 13 the coefficient of variation (CV) of total annual precipitation for four dry and four wet provinces for the near and far future. The CV is an important indicator, as even small changes in it could indicate relatively large changes in the probability of occurrence of extreme events. In general, for the near future, the $\mathrm{CVs}$ of total precipitation for wet provinces
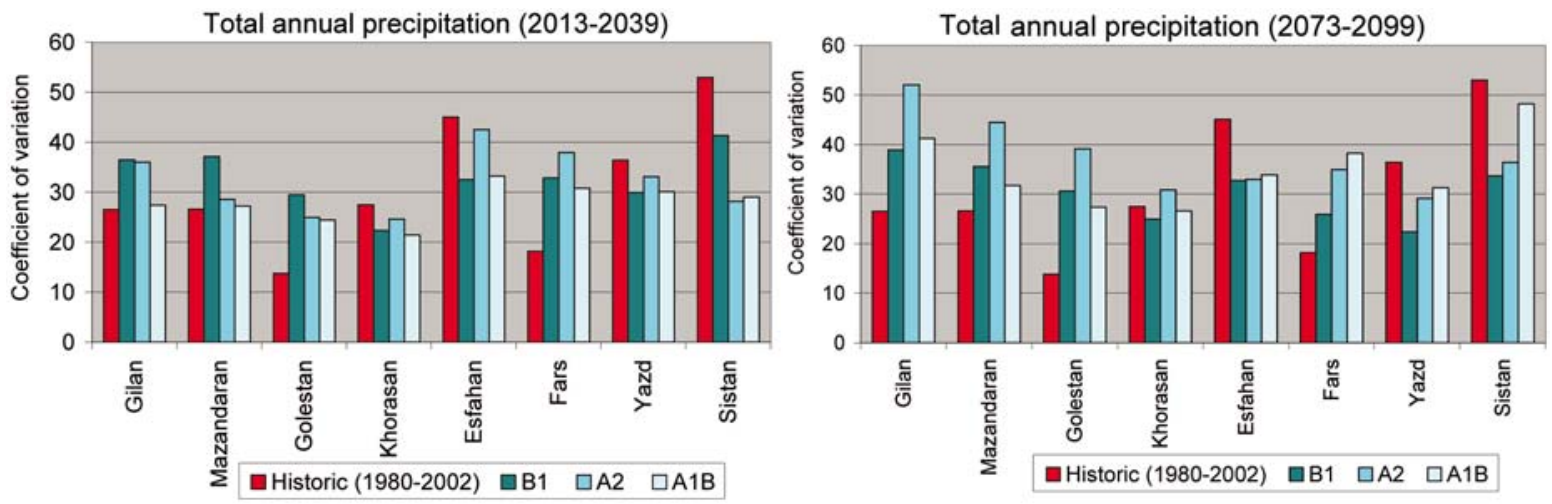

Figure 13. Coefficient of variation of total annual precipitation for wet and dry provinces based on different climate scenarios for near and far future periods. 

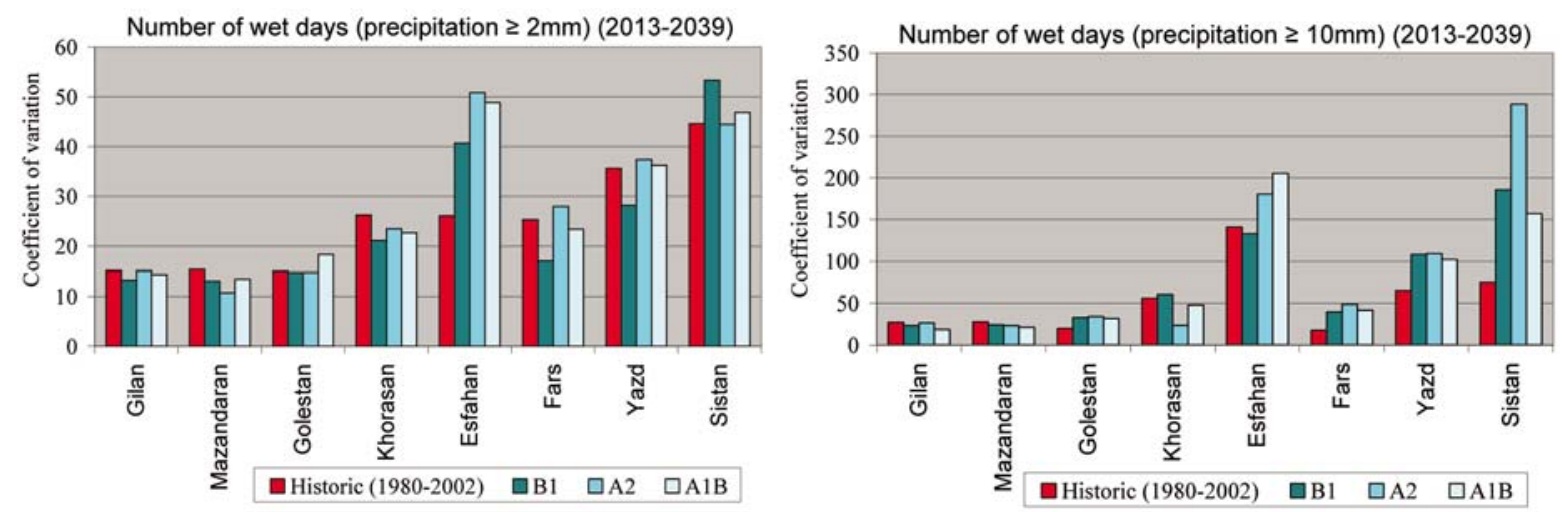

Figure 14. Coefficient of variation of the number of wet days. Shown are (left) precipitation $\geq 2 \mathrm{~mm} \mathrm{~d}^{-1}$ and (right) precipitation $\geq 10 \mathrm{~mm} \mathrm{day}^{-1}$, for wet and dry provinces.

(Gilan, Mazandaran, Golestan) are larger than the historic ones. This indicates a stronger year-to-year variation in total precipitation in these provinces. For example, for the province of Gilan, scenario A2 predicts total rainfall of larger than $4000 \mathrm{~mm}$ in some years and smaller than $650 \mathrm{~mm}$ in others. In dry provinces, except for Fars, the year-to-year variations in total precipitation seem to be smaller. The same trend could be seen for the far future but with more pronounced differences with the historic CVs.

[36] In Figure 14, we plotted the CV of the number of wet days per year for precipitations of $\geq 2 \mathrm{~mm}$ and $\geq 10 \mathrm{~mm} \mathrm{~d}^{-1}$. Only Esfahan shows a substantially larger CV for $\geq 2 \mathrm{~mm} \mathrm{~d}^{-1}$ rainfalls, while other provinces show more or less similar or smaller variations. For $\geq 10 \mathrm{~mm} \mathrm{~d}^{-1}$ rainfall, however, the $\mathrm{CV}$ is much larger for the dry provinces, indicating intermittent extreme events.

[37] Finally, in Figure 15 we plotted the CVs of maximum temperature for a typical wet and a typical dry province. In general, in the wet provinces the daily variation of maximum temperature is the same or smaller in different months, while in dry provinces this is larger, indicating some extreme high temperatures. The same was true for minimum temperature (not shown). We have also studied the CV of the difference of maximum and minimum temperature. While this variation was slightly smaller in wet provinces, it was slightly larger in dry provinces. Further and more detailed research at a regional scale is needed to quantify the exact effect of these changes on the crop production and biodiver- sity of the region. In section 4 we highlight some general implications of the changes in the future climate.

\section{Implications of the Climate Change Impact}

[38] Flooding in the northern and western part of the country is historically a common occurrence. Torrential rains during August 2001 triggered devastating floods that damaged rice, cotton, and wheat producing areas of Golestan and Khorasan provinces (see http://www.unisdr.org/eng/ country-inform/reports/Iran-report.pdf). These floods damaged thousands of hectares of farmland in Iran, claimed hundreds of lives, and washed away roads and houses, causing millions of dollars in damage. Similar floods were reported again in January 2004 along the western side of the Zagros Mountains in the western part of the country. A further increase in precipitation could increase the frequency and intensity of floods in the wet regions of the country. It is evident from the changes in precipitation (Figure 5) and blue water resources (Figure 6), as well as the increases in the number of large rainfall events (Figures 9 and 10), that the northern and western regions of the country will experience larger and more intense flooding events.

[39] Drought is estimated by the United Nation to have cost Iran 3.5 billion dollars in 2000, and midyear estimates for 2001 were already at 2.5 billion dollars (Tehran Times, July 2001, p. 4). In July 2001, fifty villages in Kerman Province in central Iran were evacuated for lack of water
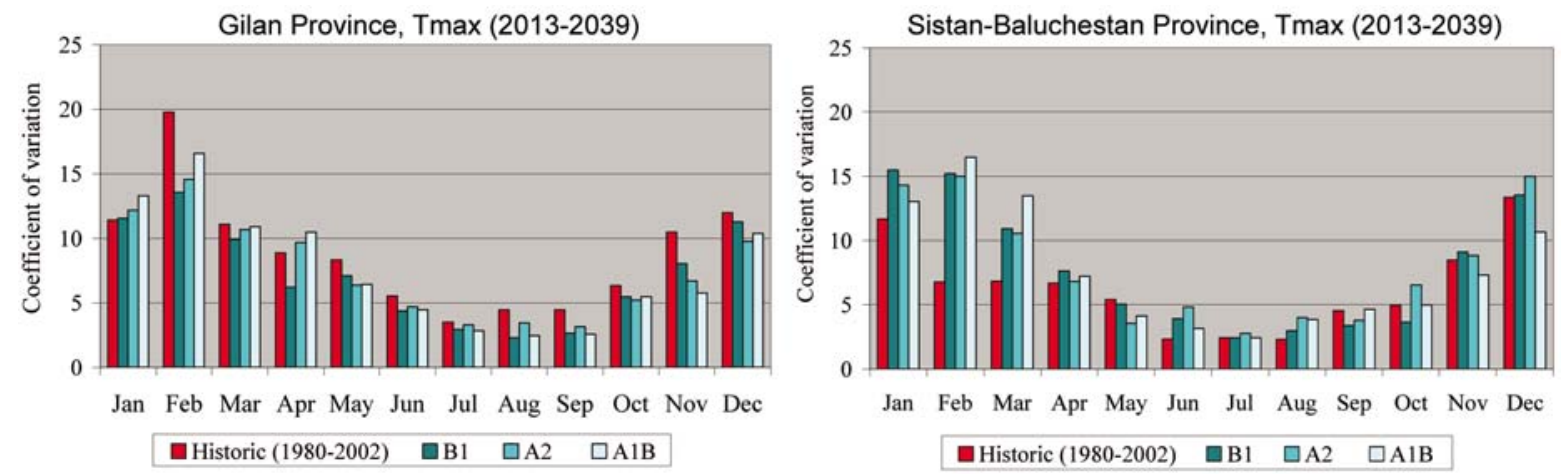

Figure 15. Coefficient of variation for maximum temperature in different months for a wet and a dry province. 
[Foltz, 2002]. Over 1 million head of livestock perished throughout the country in 2000 due to drought, and $3 \times 10^{6} \mathrm{t}$ of wheat and barley were lost. A further decrease in precipitation could increase the frequency and intensity of droughts in the dry regions of the country. It is again evident from our analysis that the southern and eastern regions of the country will experience lesser rainfalls (Figure 5), smaller aquifer recharges, and longer periods without a major rainfall event (Figures 11 and 12). Hence they are susceptible to more severe drought conditions.

[40] In many parts of Iran, the water supply solely depends on groundwater. During the past two decades an overexploitation of this resource has caused a drawdown in water table in most of the 600 aquifers in Iran [Motagh et al., 2008]. Groundwater quality, on the other hand, has also been degrading continuously because of agricultural and industrial activities in most regions of the country [Tizro and Voudouris, 2008]. Our analysis shows a decrease in groundwater recharge in water scarce regions of south and east. As much of the irrigated wheat is grown in the southern and eastern regions, climate change will have a significant negative impact on the wheat production of the country as groundwater recharge decreases.

[41] Our analysis of crop yield, however, shows small but statistically insignificant increases in winter wheat yield for most provinces. The small increase is probably due to the larger soil moisture, temperature, and more important, air $\mathrm{CO}_{2}$ concentration. According to the global geographic distribution map of major crops [Leff et al., 2004], which has a spatial resolution of 30 arc-min, and our findings, about $53 \%$ of the area under cultivation of wheat in Iran is located in water-scarce subbasins. Of the total wheat production in the country, $50 \%$ of irrigated and rain-fed wheat is produced in water-scarce regions. Although the impact on rain-fed yield appears to be small as the result of changes in temperature and rainfall patterns, the impact on irrigated yield is expected to decrease yield substantially in the dry regions of the country because of the decrease in blue water resources (Figure 6), which is river discharge plus groundwater recharge.

[42] Although we did not simulate water quality, increased precipitation in the northern and western parts of the county may increase the risk of water source contamination from sewage overflows, and runoff from agricultural land and urban areas as well as increased sediment and nonpoint source pollutant loadings to water courses. As our hydrological model was not calibrated for sediment yield, we could not quantify the impact of climate change on soil erosion. As soil erosion is already large in the country [Rostamian et al., 2008], areas with larger amounts of rainfall are expected to have even larger soil erosion, affecting crop yield, sedimentation problems in the reservoir, and river water quality. On the other hand, prolonged droughts may result in smaller river discharges and a decline in reservoir levels, causing water quality deterioration as nutrients and contaminants become more concentrated in reduced volumes with longer water residence times. Warmer water temperatures may have further direct impacts on water quality, such as increasing algae growth and reducing dissolved oxygen concentrations. Coldwater species, such as trout, are particularly susceptible to warm-water temperatures, and increasingly frequent warmwater conditions could bring new challenges to the way managed river systems are controlled. In addition, evaporative water losses could increase the salinity of soils in irrigated areas and surface waters, especially in lakes and reservoirs with long residence times. Contaminants tend to accumulate on land surfaces during prolonged droughts. Pulses of contaminated runoff can occur when precipitation returns. Water quality impacts are therefore likely to be rather complex and will vary with the physical, geographical, and biological details of each water supply.

[43] As the SWAT hydrologic model was run for 506 subbasins across the country and daily time steps, a substantial amount of information is generated for each subbasin. Of these, we provided an overview of the impact of climate change on various hydrologic components for the whole country. These analyses could be very useful in strategic planning of water resources management and crop production for future years. As different subbasins are affected differently, a number of management options could be considered in order to alleviate the climate change impact on the country as a whole. In terms of food security, these could include changes in the structure of crop production (land use change) and intracountry virtual water trade between subbasins (or provinces) utilizing local comparative advantages. These are the subjects of our continuing studies.

\section{References}

Abbaspour, K. C. (2007), User manual for SWAT-CUP, SWAT calibration and uncertainty analysis programs, 93 pp., Eawag: Swiss Fed. Inst. of Aquat. Sci. and Technol., Dübendorf, Switzerland. (Available at http:// www.eawag.ch/organisation/abteilungen/siam/software/swat/index_EN)

Abbaspour, K. C., J. Yang, I. Maximov, R. Siber, K. Bogner, J. Mieleitner, J. Zobrist, and R. Srinivasan (2007), Modelling hydrology and water quality in the pre-alpine/alpine Thur watershed using SWAT, J. Hydrol., 333, 413-430, doi:10.1016/j.jhydrol.2006.09.014.

Ardakanian, R. (2005), Overview of water management in Iran, in Water Conservation, Reuse, and Recycling: Proceedings of an Iranian-American Workshop, pp. 18-33, Natl. Acad. Press, Washington, D. C.

Arnell, N. W., M. J. L. Livermore, S. Kovats, P. E. Levy, R. Nicholls, M. L. Parry, and S. R. Gaffin (2004), Climate and socio-economic scenarios for global-scale climate change impacts assessments: Characterising the SRES storylines, Global Environ. Change, 14, 3-20, doi:10.1016/ j.gloenvcha.2003.10.004.

Arnold, J. G., R. Srinivasan, R. S. Muttiah, and J. R. Williams (1998), Large area hydrologic modeling and assessment: Part 1. Model development, J. Am. Water Resour. Assoc., 34(1), 73-89, doi:10.1111/j.17521688.1998.tb05961.x.

Caballero, Y., S. Voirin-Morel, F. Habets, J. Noilhan, P. LeMoigne, A. Lehenaff, and A. Boone (2007), Hydrological sensitivity of the Adour-Garonne river basin to climate change, Water Resour. Res., 43, W07448, doi:10.1029/2005WR004192.

Calanca, P., A. Roesch, K. Jasper, and M. Wild (2006), Global warming and the summertime evapotranspiration regime of the Alpine region, Clim. Change, 79(1-2), 65-78, doi:10.1007/s10584-006-9103-9.

Cuo, L., D. P. Lettenmaier, M. Alberti, and J. E. Richey (2009), Effects of a century of land cover and climate change on the hydrology of the Puget Sound basin, Hydrol. Processes, 23(6), 907-933, doi:10.1002/hyp.7228.

Diaz-Nieto, J., and R. L. Wilby (2005), A comparison of statistical downscaling and climate change factor methods: Impacts on low flows in the river Thames, United Kingdom, Clim. Change, 69, 245-268, doi:10.1007/s10584-005-1157-6.

Eckhardt, K., and U. Ulbrich (2003), Potential impacts of climate change on groundwater recharge and streamflow in a central European low mountain range, J. Hydrol., 284, 244-252.

Falkenmark, M., and J. Rockstrom (2006), The new blue and green water paradigm: Breaking new ground for water resources planning and management, J. Water Res. Plann. Manage., 132(3), 129-132.

Falkenmark, M., J. Lundquist, and C. Widstrand (1989), Macro-scale water scarcity requires micro-scale approaches: Aspects of vulnerability in semi-arid development, Nat. Resour. Forum, 13(4), 258-267. 
Faramarzi, M., K. C. Abbaspour, R. Schulin, and H. Yang (2009), Modelling blue and green water resources availability in Iran, Hydrol. Processes, 23(3), 486-501, doi:10.1002/hyp.7160.

Foltz, R. C. (2002), Iran's water crisis: Cultural, political, and ethical dimensions, J. Agric. Environ. Ethics, 15, 357-380, doi:10.1023/ A:1021268621490.

Fontaine, T. A., J. F. Klassen, T. S. Cruickshank, and R. H. Hotchkiss (2001), Hydrological response to climate change in the Black Hills of South Dakota, USA, Hydrol. Sci. J., 46, 27-40.

Food and Agriculture Organization (FAO) (1995), The digital soil map of the world and derived soil properties, version 3.5 [CD-ROM], Rome.

Food and Agriculture Organization (FAO) (2005), Statistical database, Rome. (Available at http://faostat.fao.org/)

Fu, G., S. P. Charles, N. R. Viney, S. L. Chen, and J. Q. Wu (2007), Impacts of climate variability on stream-flow in Yellow River, Hydrol. Processes, 21(25), 3431-3439, doi:10.1002/hyp.6574.

Gosain, A. K., S. Rao, and D. Basuray (2006), Climate change impact assessment on hydrology of Indian river basins, Curr. Sci., 90, 346-353.

Hargreaves, G., and Z. A. Samani (1985), Reference crop evapotranspiration from temperature, Appl. Eng. Agric., 1, 96-99.

Intergovernmental Panel on Climate Change (IPCC) (2007), Climate Change 2007: Impacts, Adaptation, and Vulnerability-Contribution of Working Group II to the Third Assessment Report of the Intergovernmental Panel on Climate Change, edited by M. L. Parry et al., Cambridge Univ. Press, Cambridge, U. K.

Jyrkama, M. I., and J. F. Sykes (2007), The impact of climate change on spatially varying groundwater recharge in the Grand River watershed (Ontario), J. Hydrol., 338(3-4), 237-250, doi:10.1016/j.jhydrol. 2007.02.036.

Keshavarz, A., S. Ashrafi, N. Hydari, M. Pouran, and E. Farzaneh (2005), Water allocation and pricing in agriculture of Iran, in Water Conservation, Reuse, and Recycling: Proceedings of an Iranian-American Workshop, pp. 153-172, Natl. Acad. Press, Washington, D. C.

Krause, P., D. P. Boyle, and F. Bäse (2005), Comparison of different efficiency criteria for hydrological model assessment, Adv. Geosci., 5, 89-97.

Leff, B., N. Ramankutty, and J. A. Foley (2004), Geographic distribution of major crops across the word, Global Biogeochem. Cycles, 18, GB1009, doi:10.1029/2003GB002108.

Motagh, M., T. R. Walter, M. A. Sharifi, E. Fielding, and A. J. Schenk (2008), Land subsidence in Iran caused by widespread water reservoir overexploitation, Geophys. Res. Lett., 35, L16403, doi:10.1029/ 2008 GL033814.

Neitsch, S. L., J. G. Arnold, J. R. Kiniry, J. R. Williams, and K. W. King (2002), Soil and Water Assessment Tool theoretical documentation version 2000, Rep. TR-191, 458 pp., Tex. Water Resour. Inst., College Station.

Nunes, J. P., J. Seixas, J. J. Keizer, and A. J. D. Ferreira (2009), Sensitivity of runoff and soil erosion to climate change in two Mediterranean watersheds: Part I. Model parameterization and evaluation, Hydrol. Processes, 23(8), 1202-1211, doi:10.1002/hyp.7247.

Olivera, F., M. Valenzuela, R. Srinivasan, J. Choi, H. D. Cho, S. Koka, and A. Agrawal (2006), ArcGIS-SWAT: A geodata model and GIS interface for SWAT, J. Am. Water Resour. Assoc., 42(2), 295-309, doi:10.1111/ j.1752-1688.2006.tb03839.x.

Rijsberman, F. R. (2006), Water scarcity: Fact or fiction?, Agric. Water Manage., 80, 5-22, doi:10.1016/j.agwat.2005.07.001.
Ritchie, J. T. (1972), A model for predicting evaporation from a row crop with incomplete cover, Water Resour. Res., 8, 1204-1213, doi:10.1029/ WR008i005p01204.

Rostamian, R., A. Jaleh, M. Afyuni, S. F. Mousavi, M. Heidarpour, A. Jalalian, and K. C. Abbaspour (2008), Application of SWAT model for estimating runoff and sediment in a mountainous watershed in central Iran, Hydrol. Sci. J., 53, 977-988, doi:10.1623/hysj.53.5.977.

Schuol, J., K. C. Abbaspour, R. Sarinivasan, and H. Yang (2008a), Estimation of freshwater availability in the West African sub-continent using the SWAT hydrologic model, J. Hydrol., 352, 30-49, doi:10.1016/j.jhydrol. 2007.12.025.

Schuol, J., K. C. Abbaspour, R. Srinivasan, and H. Yang (2008b), Modelling blue and green water availability in Africa at monthly intervals and subbasin level, Water Resour. Res., 44, W07406, doi:10.1029/ 2007WR006609

Scibek, J., and D. M. Allen (2006), Modeled impacts of predicted climate change on recharge and groundwater levels, Water Resour. Res., 42, W11405, doi:10.1029/2005WR004742.

Serrat-Capdevila, A., J. B. Valdes, J. G. Perez, K. Baird, L. J. Mata, and T. Madock III (2007), Modeling climate change impacts - and uncertaintyon the hydrology of a riparian system: The San Pedro Basin (Arizona/ Sonora), J. Hydrol., 347(1-2), 48-66, doi:10.1016/j.jhydrol.2007. 08.028 .

Stonefelt, M. D., T. A. Fontaine, and R. H. Hotchkiss (2000), Impacts of climate change on water yield in the Upper Wind River Basin, J. Am. Water Resour. Assoc., 36, 321-336, doi:10.1111/j.1752-1688.2000. tb04271.x.

Thomas, D. S. G., C. Twyman, and H. Osbahr (2007), Adaptation to climate change and variability: Farmer responses to intra-seasonal precipitation trends in South Africa, Clim. Change, 83(3), 301-322, doi:10.1007/s10584-006-9205-4.

Tizro, A. T., and K. S. Voudouris (2008), Groundwater quality in semi-arid region of the Chahardouly Basin, West Iran, Hydrol. Processes, 22(16), 3066-3078, doi:10.1002/hyp.6893.

Wilby, R. L., and I. Harris (2006), A framework for assessing uncertainties in climate change impacts: Low-flow scenarios for the River Thames, UK, Water Resour. Res., 42, W02419, doi:10.1029/2005WR004065.

Wilby, R. L., H. Hassan, and K. Hanaki (1998), Statistical downscaling of hydro-meteorological variables using general circulation model output, J. Hydrol., 205(1-2), 1-19, doi:10.1016/S0022-1694(97)00130-3.

Williams, J. R., C. A. Jones, and P. T. Dyke (1984), A modeling approach to determining the relationship between erosion and soil productivity, Trans. ASAE, 27(1), 129-144.

Xiong, K. G., J. Yang, S. Q. Wan, G. L. Feng, and J. G. Hu (2009), Monte Carlo simulation of the record-breaking high temperature events of climate change, Acta Phys. Sinica, 58(4), 2843-2852.

Yang, H., P. Reichert, K. C. Abbaspour, and A. J. B. Zehnder (2003), A water resources threshold and its implications for food security, Environ. Sci. Technol., 37(14), 3048-3054, doi:10.1021/es0263689.

Yang, J., P. Reichert, K. C. Abbaspour, and H. Yang (2008), Comparing uncertainty analysis techniques for a SWAT application to Chaohe Basin in China, J. Hydrol., 358, 1-23, doi:10.1016/j.jhydrol.2008.05.012.

K. C. Abbaspour, M. Faramarzi, S. S. Ghasemi, and H. Yang, Eawag: Swiss Federal Institute of Aquatic Science and Technology, Ueberlandstrasse 133, Duebendorf CH-8600, Switzerland. (abbaspour@eawag.ch) 